УДК 327.7

DOI 10.18413/2687-0967-2020-47-1-194-201

\title{
НОВЫЕ ПОДХОДЫ В ФОРМИРОВАНИИ ПОЛИТИКИ ИНТЕГРАЦИИ МИГРАНТОВ ЕВРОПЕЙСКОГО СОЮЗА
}

\section{NEW APPROACHES IN THE INTEGRATION POLICY OF MIGRANTS IN EUROPEAN UNION}

\author{
Ф.М. Рамазанова ${ }^{1}$, К.Н. Лобанов ${ }^{2}$ \\ F.M. Ramazanova ${ }^{1}$, K.N. Lobanov ${ }^{2}$ \\ 1) Среднерусский институт управления - филиала РАНХиГС, \\ Россия, 302028, г. Орѐл, б. Победы, 5а \\ ${ }^{2)}$ Белгородский юридический институт МВД России имени И.Д. Путилина, \\ Россия, 308024 г. Белгород, ул. Горького, 71
}

${ }^{1)}$ Orel branch of Russian Presidential Academy of National Economy and Public Administration, Boulevard Pobedy, 5A, Orel, 302028, Russia

The I.D. Putilin Belgorod Institute of Law, 71 Gorkogo St, Belgorod, 308024, Russia

E-mail: fati.ramazanova@gmail.com; Lobanov-pol@yandex.ru

\begin{abstract}
Аннотация
В данной статье представлена практика Европейского Союза в регулировании политики по интеграции мигрантов с учѐтом социального и антропологического аспектов. Работа опирается на проведенные исследования во Франции и Бельгии и их опыт в разрешении поставленных задач. В настоящей статье уделено внимание формированию правовой основы национальной политики в области интеграции иммигрантов. В ходе работы были охарактеризованы современные формы интеграционной политики Европейского Союза, в частности Франции и Бельгии, подвергнуты анализу исследования в области антропологии. Предложено авторское видение на разрешение проблем в сфере миграции и интеграции иммигрантов на территории Европейского Союза.
\end{abstract}

\begin{abstract}
In article presents an attempt to consider the integration policy of the European Union within the social and anthropological aspects. The integration of Muslim migrants remains actual issue for the past decades, with their political participation being a strong focus. I used my experience, which was forged in the different countries I worked in, to develop a common conception of integration policy for the European Union as whole. The investigation structured within a theoretical framework and composed it using a comparative perspective in the social and political spheres. In the current study have applied strong working methodology for the collection and the analysis of specific. To examine the results of the implemented policies (study of migration centers' reports: integration in the labor market, ongoing programs and activities, language proficiency), the statistical data to assess the effects on migrants was used. Modification of interior legislation towards common regime and conditions in the EU might resolve the further problems with territorial concentration of migrants.
\end{abstract}

Ключевые слова: иммиграция, интеграционная политика, Европейский Союз, Франция, Бельгия. Keywords: immigration, integration policy, European Union, France, Belgium.

Общие тенденции интеграционной политики начали своѐ формирование под влиянием развития процессов интеграции непосредственно между странами Европейского Союза (ЕС), что в последствии привело к развитию общих направлений. Стоит отметить тот факт, что в настоящее время так и не существует единой концепции интеграционной политики имми- 
грантов, что широко обсуждается в научных кругах Западной Европы. Данная тема обретает более актуальный характер в условиях современного миграционного кризиса. Сложность развития общей концепции интеграционной политики иммигрантов для ЕС состоит в многогранности Европы, еѐ миграционной истории, экономики и политического строя. В работах современных западных авторов всѐ чаще поднимается вопрос законодательного права в рамках EC [Adam, 2013], насколько государство свободно в своих решениях [Orgad, 2016], и как при этом сохранять баланс с общими принципами демократии EC [Zbigniew, 2012].

Первая задача исследования состоит в определении базиса наднациональной политики интеграции мигрантов в Европейском союзе. Для решения поставленной задачи в первую очередь стоит обратиться к опыту таких стран, как Франция и Бельгия, где политика по интеграции мигрантов представлена в соответствии с государственной концепцией. На основе почти 50-летнего опыта рассматриваемых стран по интеграции мигрантов в принимаемое общество и личных наблюдений в ходе исследований в работе представлен авторский взгляд на пути адаптации новоприбывших и уже натурализованных мигрантов.

Методом системного анализа были рассмотрены основные структурные элементы интеграционной политики мигрантов на европейском пространстве. Важное методологическое значение для системного анализа механизмов интеграционной политики имело выявление ключевых элементов в национальной политике, определяющих результативность проводимых мер на основе движения от частных примеров к общим закономерностям и выводам. Он позволяет проанализировать специфику, общие закономерности, фундаментальные тенденции и взаимосвязи социальных и политических процессов на территории исследуемых стран Европы. Эмпирическую базу исследования составили данные, полученные в ходе научных стажировок в Эстонии, Бельгии и Франции в виде серии проведѐнных интервью среди мигрантов.

\section{Интеграционная политика $\mathrm{EC}$ и еѐ реализация в регионах}

Интеграционная политика западноевропейских стран начала своѐ формирование во второй половине XX века, когда статус «временного пребывания» рабочих мигрантов перешел на «постоянное место жительства». В Европейском Союзе интеграционная политика мигрантов является национальной компетенцией, то есть регулируется членамигосударствами обособленно. Однако после подписания Лиссабонского договора в 2007 году Европейские институты получили полномочия проводить стимулирование и поддержку государств ЕС в осуществлении интеграции граждан из третьих стран ${ }^{103}$. С вступлением в силу в 1999 году Амстердамского соглашения интеграция мигрантов из стран вне ЕС находится под влиянием европейской политики - ЕС может предпринимать действия по борьбе с дискриминацией, в том числе основанной на расовой и этнической принадлежности, по религиозным или иным убеждениям ${ }^{104}$.

До 2004 года общая интеграционная политика была закреплена в Тамперской программе $^{105}$, разработанной ЕС, о предоставлении государствами-членами союза гражданам третьих стран тех же прав, что и гражданам ЕС. Кроме того, в программе отражены распоряжения о долгосрочных резидентах стран и положения касательно объединения семьи. Для долгосрочных резидентов вводится единый статус с целью обеспечения равных возможностей: всем лицам, законно проживающим более пяти лет на территории ЕС, должен быть предоставлен долгосрочный вид на жительство. В том числе, мигрант имеет право подать документы на восстановление семьи и может привезти своего супруга и несовершеннолетних детей.

Процессом развития общей иммиграционной политики явилось принятие Советом ЕС по вопросам правосудия и внутренним делам в 2004 году общих базовых принципов в сфере интеграционной политики. Общие базовые принципы руководствуются большинством дей-

\footnotetext{
${ }^{103}$ Treaty of Lisbon. 2007. Official Journal of the European Union, № 360, 231 p.

104 Treaty of Amsterdam. 1997. Official Journal of the European Communities, № 340, 111 p.

105 T ampere Program 2002. The Information and Communication unit of the Directorate-General Justice and Home Affairs of the European Commission, B-1049 Brussels, 4 p.
} 
ствий ЕС в области интеграции и представляют собой основополагающий базис развития общей интеграционной политики. Одиннадцать установленных принципов формулируют интеграцию как динамичный двусторонний процесс взаимной адаптации иммигрантов и местных жителей при условии уважения демократических ценностей ЕС. Также в документе подчеркивается значение сферы занятости, знания локального языка, местных органов власти, культурного обмена, образовательного процесса, участия в демократических процессах, равных возможностей и признания ключевой роли интеграционной политики на всех уровнях власти. Спустя 10 лет государства-участники возобновили обязательства в 2014 году.

Несмотря на попытки ЕС урегулировать интеграционную политику в соответствии с демократическими принципами и ценностями союза, проблемы интеграции остаются всѐ ещѐ значительными. Как уже сказано выше, интеграционная политика находится в компетенции государств-членов ЕС, но обязана придерживаться установленных демократических принципов. В то же время, если мы внимательно посмотрим на внутреннюю политику отдельных стран ЕС, то можно заметить полное расхождение концепций интеграции инокультурных мигрантов.

\section{Франция}

Рассмотрим случай Франции, где главенствует концепция «французского гражданина», т. е. это одна из немногих стран с ассимиляционной политикой. Политика ассимиляции подразумевает полное включение мигранта в гражданскую и культурную жизнь страны, слияние его идентичности с общепринятыми на государственном уровне понятиями гражданина. Франция является единственной страной ЕC, не подписавшей рамочную конвенцию о защите национальных меньшинств, объясняя это равенством всех перед французским государством ${ }^{106}$. Переезд в страну, принятие местного законодательства и гражданских ценностей, последующее получение гражданства - уже, по мнению французских структур, являются завершѐнным процессом интеграции. Этот подход был изменен в 1970-х годах, когда государственные органы начали рассматривать культурные особенности мигрантов. Однако с 70-х годов подход к иностранным гражданам, желающим остаться на постоянное место жительства, претерпевал диаметрально противоположные изменения от ассимиляции к концепции мультикультуризма и обратно. На сегодняшний день интеграционная политика Франции ориентирована на максимальное включение мигранта во французский социум посредством образовательных программ, реализуемых ответственными за то органами [Lapeyronnie, 2009, p. 70].

C точки зрения французского правительства, гражданин должен обладать определѐнной идентичностью, которая определяется общим признанием ее основополагающих принципов. Характеристики личности каждого человека являются частью частного, четко определенного публичного пространства. Что касается частных критериев или характеристик, таких как раса, религия, происхождение или общественное мнение, государство воспринимает эти элементы частного характера. Это объясняет, почему государственные учреждения не могут собирать статистические данные, дающие информацию или позволяющие заключать определенные личные характеристики своих граждан ${ }^{107}$. Четкое уважение этого принципа равенства следует рассматривать в свете этого самопровозглашенного невмешательства республики. Это «невмешательство» стало более видимым в последние годы, особенно в отношении государства к религии. Таким образом, секуляризм стал одним из основополагающих принципов Французской Республики с момента его введения в практику в XX веке.

Исходя из этого контекста, за всю свою долгую историю миграции Франция никогда не ставила себе вопрос интеграции иммигрантов. По мнению французского правительства, непосредственно приезд в республику уже представляет собой начало интеграционного процесса, а точнее, ассимиляцию с принципами республики.

\footnotetext{
${ }^{106}$ Framework Convention for the Protection of National Minorities. 1995. European Treaty, № 194, 27 p.

${ }^{107}$ Loi $\mathrm{n}^{\circ}$ 78-17 du 6 janvier 1978 relative à l'informatique, aux fichiers et aux libertés. URL: https://www.cnil.fr/fr/loi-78-17-du-6-janvier-197 8-modifiee (дата обращения 20 января 2019).
} 


\section{Бельгия}

Пример соседней страны, Бельгии, позволяет нам наблюдать как в рамках одного государства сосуществует совершенно две разные концепции интеграционной политики. Последовательная трансформация Бельгии из унитарного государства в федеральное, с высоким уровнем автономии для федеральных структур, началось с фламандского национального движения и ответной реакции франкоговорящей части [Swenden, Jans, 2006, p. 877]. В 1980 годах интеграционная политика мигрантов переходит под юрисдикцию регионов. Начавшиеся дебаты по вопросам единой модели интеграционной политики обозначили ещѐ более явственное разделение мнений и невозможность определения общего направления [Martiniello, 1995, p. 24]. Как результат, региональная интеграционная политика Бельгии поделена на валлонский подход ассимиляции против фламандского мультикультуризма [Rea, Jacobs, 2005 p. 36].

Сложность и территориальное пересечение субъектов являются результатом компромисса между требованиями фламандской партии, стремящейся к культурной автономии и созданию сообществ, и партии франкофонов, отстаивающей экономическую автономию и создание регионов. В то же время фактическое создание регионов было включено в повестку второй государственной реформы 1980 года, и во время третьей реформы в 1989 году - относительно брюссельского региона. На территории брюссельского региона комиссии французского (COCOF) и фламандского (VGC) сообществ являются компетентными объединениями в сфере единого языка. Каждая из комиссий включает в себя ассамблею и один исполнительный орган, называемый коллегией, которая состоит из депутатов и министров Брюссельского региона. Комиссии сообществ представляют собой учредительную власть, в основном, в области сообществ. Однако существует одно большое различие между Комиссиями сообществ франкофонов и нирландофонов. В отличие от VGC, COCOF получает законодательную власть в 1993 году, которая ему была передана французскими кантонами (социальная политика, интеграция иммигрантов, здравоохранение) [Adam, 2013, p. 204].

Федеральное государство остаѐтся компетентным во многих областях, имеющих одно немаловажное значение для интеграции иммигрантов. Конституция в том числе определяет компетенцию законодательного органа для правовой системы относительно получения гражданства и доступа к политическим правам (участие в выборах). Интеграционная политика, а также, в частности, право на въезд, пребывание, размещение и депортация иностранцев, так же, как и нормы касательно их трудоустройства, остаются тоже в компетенции федерального органа.

Структура бельгийского государства была разработана, насколько это возможно, с целью избежания внутригосударственной кооперации между федеральным правительством и федеральными структурами. Таким образом, федеральные структуры имеют полную законодательную и исполнительную власть в переданных им областях управления. Между законодательными актами федерального правительства (законами) и федеральными структурами (постановлениями) нет нормативной иерархии. Несмотря на желание избежать всяческую кооперацию между институтами, данное явление всѐ же имеет место в государственной политике.

Исходя из вышеуказанных примеров, мы можем наблюдать расхождение интеграционной политики мигрантов на периферии ЕС. Необходимость изменения общего направления политики интеграции постепенно приводит к переосмыслению ведущих факторов в работе над будущими проектами.

\section{Новые подходы в интеграционной политике мигрантов}

Все страны ЕС сходятся во мнении, что вовлечение иммигрантов в рынок труда, так же, как и достаточный уровень образования, являются наиболее важными вопросами для успешной интеграции. На деле некоторые из основных факторов интеграции могут распространяться на упомянутые области. Высокий уровень вовлечения в рынок труда и коэффициент распространения образования рассматриваются как потенциальная гарантия получения дохода, и, как следствие, возможность полноценного участия в жизни принимающего 
общества без государственной поддержки. Так, горизонтальная, или «непрямая европеизация» предоставляет больше возможностей для негосударственных групп таких, как политические партии, общественные группы, некоммерческие объединения и интеллигенция группы людей, которые важны в политике развития [Vink, Graziano, 2008, p. 18].

Уже в конце XX в. параллельно вместе с дебатами об интеграционной политике в странах ЕС происходит переосмысление существующих законодательств по вопросам интеграции и натурализации. Исследования на тему интеграционной политики зачастую переходят в разряд философии и этики, поскольку затрагивают моральный аспект, где особое влияние оказали работы Р. Брубейкера [Brubaker, 1992], Д. Раца [Raz, 1975], К. Джопке [Joppke, 2010], Д. Каренса [Carens, 2015].

Несмотря на значительные политические и идеологические разногласия по вопросам интеграции мигрантов, Я. Ниессен [Niessen, 2000, р.119], один из ведущих современных исследователей в области интеграционной политики мигрантов, находит большое количество схожих путей разрешения среди государств-членов ЕС в их усилиях по еѐ содействию. Во всех странах ЕС были приняты законы, регулирующие право на законный вид местожительства, обеспечение доступа к трудоустройству, образование и политическую активность. Автор находит также возрастающее сходство в политике натурализации, а также в усилиях государств-членов по борьбе с дискриминацией, расизмом и ксенофобией.

Большинство государств-членов ЕС рассматривают равный доступ к институтам социального обеспечения как основное условие интеграции иммигрантов. Большинство государств-членов также считают, что они важны в контексте политики интеграции.

Однако, несмотря на кажущуюся схожесть за счѐт подобных законопроектов, которые, по сути, должны быть, безусловно, выполнены членами-государствами в силу принятия общих демократических ценностей и условий ЕС, подходы в интеграционной политике весьма различны. Если южные страны ЕС склонны подчеркивать натурализацию как важнейшее условие интеграции, то у северных стран подход противоположный. В восприятии последних, натурализация не является непременным условием интеграции, однако основное внимание уделяется повышению уровня владения языком, уровня гражданской активности и поощрение контактов с местным населением.

Эта тенденция была отмечена Европейской комиссией по вопросам иммиграции, интеграции и занятости ещѐ в 2003 году: «Интеграцию следует понимать как двусторонний процесс, основанный на взаимных правах и соответствующих обязательствах граждан, проживающих на законных основаниях третьих стран, и принимающего общества, которое предусматривает полное участие иммигранта. Это подразумевает, с одной стороны, что принимающее общество несет ответственность за обеспечение формальных прав иммигрантов таким образом, чтобы индивидуум имел возможность участвовать в экономической, социальной, культурной и гражданской жизни и на другие, где иммигранты уважают основополагающие нормы и ценности принимающего общества и активно участвуют в процессе интеграции, не отказываясь от своей собственной идентичности» ${ }^{108}$.

Тем самым это указывает на неоднозначное восприятие интеграции, которое особенно заметно в странах с более устойчивой иммиграционной историей. Юридическое урегулирование иммиграции и удовлетворительная степень вовлечения различных институтов больше не являются единственными условиями для успешной интеграции. Все чаще растет осознание того, что определенная степень знания основного языка и культуры принимаемой страны является также значительным фактором в интеграции мигрантов.

Важнейшим предметом обсуждения является вопрос о том, в какой степени некоторые из стран ЕС проводят политику, основанную на насильственной ассимиляции и дискримина-

\footnotetext{
${ }^{108}$ Opinion of the European Economic and Social Committee on access to European Union Citizenship. 2003. Official Journal of the European Union, C. 208-76.

URL : https://eur-lex.europa.eu/LexUriServ/LexUriServ.do?uri=OJ:C:2003:208:0076:0081:EN:PDF (дата обращения 29 января 2020).
} 
ции этнических меньшинств в их границах, которые противоречат европейским стандартам. Следует иметь в виду, что в соответствии с этими стандартами национальные меньшинства не должны рассматриваться так же, как граждане третьих стран. Первые уже обладают теми же правами, что и все остальные граждане принимаемой страны, в то время как последние приобретают такие права лишь постепенно. Поэтому вопросы, связанные с интеграцией национальных меньшинств в некоторые из новых государств-членов, не всегда можно сравнить с интеграционными процессами иммигрантов более старших стран-членов ЕС.

В новом подходе к интеграционной политике стоит также обратиться к антропологическим исследованиям. Восприятие «мигранта» как такового за последние десять лет меняется с высокой скоростью, где момент его восприятия принимающим социумом упускается. Тем не менее, возвращаясь к исторической ретроспективе интеграционного процесса на территории Западной Европы, стоит отметить что «мигрант» всегда являлся объектом политики, но не субъектом коммуникации [Feldman, 2011, p. 248]. Проблема социальной сегрегации между правительственными структурами и мигрантами встает как сюжет обсуждений в американской библиографии, в то время как в Европе данная тема занимает свой пьедестал только в философских науках, например, в работах известного французского философа Мишеля Фуко [Foucault, 1980].

При разработке общей концепции политики по интеграции мигрантов необходимо упомянуть и о религиозной составляющей данного дискурса. Возрастающее число радикально настроенных мусульман всѐ более вызывает опасение как со стороны государства, так и со стороны местного населения, в том числе среди мусульман. Причина возрастающего числа приверженцев салафизма может зависеть от социальный-психологического и экономического факторов.

Переезд, включение в новое общество, незнание языка, ксенофобия, исламофобия, проблемы в социальной сфере зачастую предопределяют будущую картину мигранта - ассимиляция или отчуждение. Путь ассимиляции ведѐт к стиранию этнических особенностей в поведении мигранта, его отрицание собственной культуры, соотечественников, иногда даже родственников. В понимании мигранта выбранный путь ассимиляции поможет его более быстрому включению в принимающее общество, что, на самом деле, может действительно этому способствовать. Однако подобный способ коренным образом подрывает психологическую основу личности, но, что более значимо, не соответствует либерально-демократическим ценностям и устоям ЕС. Отчуждение может сопровождаться дальнейшим уходом в национализацию и радикализацию индивидуума, что приводит к ещѐ большей поляризации общества.

Обращаясь к национальному вопросу, мы найдѐм много работ европейских и американских исследований на тему этничности. В работах зарубежных исследователей красной нитью проходит мысль о конфликтах на почве националистических предрассудков [Genna, 2015; Jensen, Van Kersbergen, 2016]. Если люди обладают исключительной национальной идентичностью и враждебны по отношению к другим культурам, то они с меньшей вероятностью поддерживают интеграцию. Чтобы избежать подобного сценария, принимающим странам необходимо разработать систему включения в социум мигранта на ранних порах.

Интеграционная политика ЕС обходит психологические аспекты, ориентируясь исключительно на интересы принимающей страны. В ходе проведения исследовательской работы и работы над интеграционными аспектами было отмечено, что в разработку интеграционной политики включение исследований из области психологии и социологии являются необходимыми для успешной интеграции мигрантов.

По результатам проведенных исследований можно сделать следующие выводы:

1. Проведя теоретический и сравнительный анализ интеграционного законодательства для иммигрантов на региональном уровне в ходе исследования было выявлено расхождение проводимого государствами политического курса по отношению к законодательным актам ЕС.

2. Принимая во внимание современную ситуацию, когда диспропорция расселения иммигрантов достигает критической отметки, члены ЕС должны быть более конструктивны в проведении общего политического курса. 
3. Изменение внутренней интеграционной политики к общим условиям внутри ЕС может разрешить дальнейшие проблемы с территориальной концентрацией иммигрантов. При разработке общих направлений для успешной интеграционной политики необходимо учитывать исследования в области антропологии и психологии. Однако здесь возникает вопрос, насколько государства ЕС готовы пойти по данному пути, так как каждая страна извлекает для себя из миграционного режима нужную себе выгоду.

\section{Список литературы}

1. Adam I. Les entités fédérées belges et l'intégration des immigrés. 2013. Politiques publiques compares. Belgique, Editions de 1'Université de Bruxelles, 204.

2. Orgad L. 2016. The Cultural Defense of Nations: A Liberal Theory of Majority Rights. United Kingdom, Oxford University Press, 304.

3. Brubaker R. 1992. Citizenship and Nationhood in France and Germany. USA, Harvard University Press, 288.

4. Carens J.H. 2015. The Ethics of Immigration. USA, Oxford University Press, 364.

5. Feldman G. 2011. The Migration Apparatus: Security, Labor, and Policymaking in the European Union. USA, Stanford University Press, 248.

6. Foucault M. 1980. Power/Knowledge: Selected Interviews and Other Writings 1972- 1977. USA, Pantheon Books, 270.

7. Framework Convention for the Protection of National Minorities. 1995. European Treaty, № $194,27 \mathrm{p}$.

8. Genna G.M. 2015. Images of Europeans. Journal of International Relations and Development: $2-23$.

9. Jensen C. Van Kersbergen C.J. 2016. The Politics of Inequality. UK, Palgrave Macmillan, 200.

10. Joppke C. 2010. Citizenship and Immigration. UK, Cambridge Polity Press, 216.

11. Lapeyronnie D. 2009. L'intégration menacée - Les grands instruments d'intégration: panne, crise, disparition? Cahiers français, 352: 70-74.

12. Loi no 78-17 du 6 janvier 1978 relative à l'informatique, aux fichiers et aux libertés. Available at: https://www.cnil.fr/fr/loi-78-17-du-6-janvier-1978-modifiee (accessed 20 January 2019). $24-29$

13. Martiniello M. 1995. Philosophies de l'integration en Belgique. Homme et Migrations, 1193:

14. Niessen, J. 2000. Diversity and cohesion: New challenges for the integration of immigrants and minorities. France: Council of Europe, 119.

15. Opinion of the European Economic and Social Committee on access to European Union Citizenship. 2003. Official Journal of the European Union, C. 208-76. Available at: https://eurlex.europa.eu/LexUriServ/LexUriServ.do?uri=OJ:C:2003:208:0076:0081:EN:PDF (accessed 29 января 2019).

16. Raz J. 1975. Practical Reason and Norms. USA, Princeton University Press, 220.

17. Rea A., Jacobs D. 2005. Construction et importation des classements ethniques. Allochtones et immigrés aux Pays-Bas et en Belgique. Revue européenne des migrations internationales, 21(2): 35-59.

18. Swenden W., Jans M. 2006. Will it stay of will it go? Federalisme and the sustainability of Belguim. West European Politics, 29(5): 877-894.

19. Treaty of Amsterdam. 1997. Official Journal of the European Communities, № 340, 111 p.

20. Treaty of Lisbon. 2007. Official Journal of the European Union, № 360, 231 p.

21. Vink M.P., Graziano P. 2008. Europeanization: New Research Agendas. Basingstoke: Palgrave MacMillan, 419.

22. Zbigniew B. 2012. Strategic vision: America and the crisis of global power. USA, NY Basic Books, 224.

\section{References}

1. Adam I. Les entités fédérées belges et l'intégration des immigrés. 2013. Politiques publiques compares. Belgique, Editions de 1'Université de Bruxelles, 204.

2. Orgad L. 2016. The Cultural Defense of Nations: A Liberal Theory of Majority Rights. United Kingdom, Oxford University Press, 304. 
3. Brubaker R. 1992. Citizenship and Nationhood in France and Germany. USA, Harvard University Press, 288.

4. Carens J.H. 2015. The Ethics of Immigration. USA, Oxford University Press, 364.

5. Feldman G. 2011. The Migration Apparatus: Security, Labor, and Policymaking in the European Union. USA, Stanford University Press, 248.

6. Foucault M. 1980. Power/Knowledge: Selected Interviews and Other Writings 1972- 1977. USA, Pantheon Books, 270.

7. Framework Convention for the Protection of National Minorities. 1995. European Treaty, № 194, $27 \mathrm{p}$.

8. Genna G.M. 2015. Images of Europeans. Journal of International Relations and Development: $2-23$.

9. Jensen C. Van Kersbergen C.J. 2016. The Politics of Inequality. UK, Palgrave Macmillan, 200.

10. Joppke C. 2010. Citizenship and Immigration. UK, Cambridge Polity Press, 216.

11. Lapeyronnie D. 2009. L'intégration menacée - Les grands instruments d'intégration: panne, crise, disparition? Cahiers français, 352: 70-74.

12. Loi n ${ }^{\circ} 78-17$ du 6 janvier 1978 relative à l'informatique, aux fichiers et aux libertés. Available at: https://www.cnil.fr/fr/loi-78-17-du-6-janvier-1978-modifiee (accessed 20 January 2019).

13. Martiniello M. 1995. Philosophies de l'integration en Belgique. Homme et Migrations, 1193: 24-29.

14. Niessen, J. 2000. Diversity and cohesion: New challenges for the integration of immigrants and minorities. France: Council of Europe, 119.

15. Opinion of the European Economic and Social Committee on access to European Union Citizenship. 2003. Official Journal of the European Union, C. 208-76. Available at: https://eurlex.europa.eu/LexUriServ/LexUriServ.do?uri=OJ:C:2003:208:0076:0081:EN:PDF (accessed 29 января 2019).

16. Raz J. 1975. Practical Reason and Norms. USA, Princeton University Press, 220.

17. Rea A., Jacobs D. 2005. Construction et importation des classements ethniques. Allochtones et immigrés aux Pays-Bas et en Belgique. Revue européenne des migrations internationales, 21(2): 35-59.

18. Swenden W., Jans M. 2006. Will it stay of will it go? Federalisme and the sustainability of Belguim. West European Politics, 29(5): 877-894.

19. Treaty of Amsterdam. 1997. Official Journal of the European Communities, № 340, 111 p.

20. Treaty of Lisbon. 2007. Official Journal of the European Union, № 360, 231 p.

21. Vink M.P., Graziano P. 2008. Europeanization: New Research Agendas. Basingstoke: Palgrave MacMillan, 419. Books, 224.

22. Zbigniew B. 2012. Strategic vision: America and the crisis of global power. USA, NY Basic

\section{Ссылка для цитирования статьи Reference to article}

Рамазанова Ф.М., Лобанов К.Н. 2019. Новые подходы в формировании политики интеграции мигрантов Европейского Союза. Via in tempore. История. Политология, 47(1): 194-201. DOI 10.18413/2687-0967-2020-47-1-194-201

Ramazanova F.M., Lobanov K.N. 2019. New Approaches in the Integration policy of Migrants in European Union. Via in tempore. History and political science, 47(1): 194-201 (in Russian).

DOI 10.18413/2687-0967-2020-47-1-194-201 